This study aimed to determine the lived experiences of parents of children diagnosed with cancer in Iran.

Methods A qualitative approach was adopted using content analysis of semi-structured interviews carried out with 10 parents to capture their experiences of having children with cancer.

Results The following themes emerged from the analysis: being aghast by the diagnosis', 'living in the shadow of fear', 'uncertainty', 'struggle for taking control'.

Conclusions The findings of the study can provide nurses and other health professionals with a deeper understanding of Parents' view when they have a child suffering from cancer. It is important to health professionals involved in caring for these people. The study calls for more attention to parents of children with cancer and education to nurses.

\section{A WORK-TRAINING-UNIT ON THE NEONATAL INTENSIVE CARE UNIT (NICU). AN OPTIMAL LEARNIG CLIMATE?}

doi:10.1136/archdischild-2012-302724.1865

J Wielenga, M Hemmink, M Willemsen, C Bouwens, J Boltje. IC Neonatology, Women's and Children Clinic Academic Medical Center Amsterdam, Amsterdam, The Netherlands

Background and Aims On the NICU of the Women's and Children Clinic/Academic Medical Center in Amsterdam the Netherlands, newborns are transferred to regional hospitals for high dependency care. This had consequences for inexperienced nurses' preparation of their post graduate Intensive Care Neonatology training. These trainees had to work on the Intensive Care without the proper patients present. Therefore independency in caring was limited. To create a powerful and safe learning climate and to offer trainees the opportunity to become competent, a work-trainingunit was established.

Methods Preconditions were decided on: presence of an adequate amount of coaches, training focussing on situational coaching, four newborns, one coach and two pre-course trainees in the day or evening shift and preferably no trainees in the night shift and daily reflection and evaluation. Coaches were trained how to supervise and enhance the competency, expertise and independency of the trainees.

Results On the work-training-unit the trainees were offered the opportunity to care for post-IC and high dependency newborns, under constant supervision of their coach.

Trainees in the work-training-unit, achieved the acceptable level of functioning and usability sooner. An increase in performing nursing procedures and standard care in a uniform way was noticed. Trainees as well as coaches were extremely satisfied.

Conclusions The work-training-unit is a valuable addition to the learning possibilities of nurses as well as the organisation. It has positive side effects on work pressure, production and capacity but most of all it appears to be an optimal learning climate.

\section{LEVELS OF AWARENESS IN TEACHERS REGARDING CHILD NEGLECT AND ABUSE}

doi:10.1136/archdischild-2012-302724.1866

D Tugay. Statistical Department, Ministry of Health of Turkey, Health Resarch General Directorate, Ankara, Turkey

\footnotetext{
Aims In ourcountry, there are still no measurement tools having sufficient content and scope that aims at the awareness and any databank on this aspect, in spite of studies aimed at child neglect and abuse are maintained. With this study, it's aimed at evaluating awareness levels of teachers for child $\mathrm{n} \& \mathrm{a}$, and having gained the questionnaire in the Turkish literature.

Method In our study, "Child Abuse and Neglect Questionnaire for Teachers" that was developed byKerryann Walsh et al. has been used. The questionnaire has been applied to 1000 teachers who are
}

employed in 43 schools in the provincial centrum of Ordu, and has been completed with 400 teachers.

Results Teachers expressed that they have to report the suspicion of child n\&a in rate of $45.7 \%$ by National Education policies (Table1). A detection question of "What is the possibility of thischild being abused or neglected?" has been addressed to teachers for each of 32 stories. The average of given answers of the teachers aimed at the child n\&a in the stories is 3.01 over 5 , and is as "I am not sure". And the average of answers given related with reporting is 2.77 , and is probably between "no" and "I am not sure" (Table2). With the increase of determining the possibilities of n\&a, it's been seen that the reporting possibilities of teachers are increased (Table3).

Conclusions It could not be said that the awareness levels of teachers for child n\&a are sufficient. Therefore, the importance of education programmes for $\mathrm{n} \& \mathrm{a}$ in our country should be emphasised and a mandatory reporting procedure that is carefully systemised within the national education programmes should be conducted.

\section{EFFECT OF ALOEVERA GEL VERSUS LANOILIN OINTMENT ON NIPPLE SORE}

doi:10.1136/archdischild-2012-302724.1867

'M Gholami, ${ }^{2} \mathrm{R}$ Saeidi, ${ }^{2} \mathrm{M}$ Tafazoli. 'Neyshabur University of Medical Sciences; ${ }^{2}$ Mashhad University of Medical Sciences, Mashhad, Iran

Background and Aim A common, early postpartum concern of the breastfeeding mother is nipple pain Because of lack of effective treatment and Opponent results about lanolin, we decided to compare effect of lanolin ointment and Aloevera gel on nipple sore treatment.

Methods This clinical blind trial was performed in Mashhad, Iran from Feb 2008 to May 2009. Sampling was nonrandom and purpositive and then samples divided randomly into two groups.

Mothers were instructed to rub the preparation on their arms and if there wasn't cause allergy symptoms, rub it on the nipple after feeding the baby 3 times a day for 7 days and let to dry and don't wash it before next feeding. Researcher pretreatment, at 3rd and $7^{\text {th }}$ day filled Storr scale with interview and examination There was no any complications in mothers and infants because of drug usage.

Then data was analyzed with Spss 11.5 and Mann-witney, t student and t-paired tests.

Results A total of 100 samples enrolled with 50 samples in lanolin group and 50 samples in aloevera group.

nipple sore scoring decreased significantly at $3^{\text {rd }}$ day versus pretreatment $(\mathrm{p}=0.00)$ also at $7^{\text {th }}$ day versus pretreatment and $3^{\text {rd }}$ day $(\mathrm{p}=0.000)$.

nipple sore scoring decreased significantly at $3^{\text {rd }}$ day versus pretreatment $(p=0.00)$ also at $7^{\text {th }}$ day versus pretreatment and $3^{\text {rd }}$ day $(\mathrm{p}=0.000, \mathrm{p}=0.001)$.

Two groups were homogenous concerning at pretreatment day $(p=0.711)$, but there was a significant difference between 2 groups at $3^{\text {rd }}$ and $7^{\text {th }}$ day $(p=0.048, p=0.003)$.

Conclusion Aloe Vera is more effective than lanolin on nipple sore healing.

\section{PROBLEMS IN THE PROCESS OF WEANING IN BREAST-FED BABIES}

doi:10.1136/archdischild-2012-302724.1868

${ }^{1} \mathrm{~N}$ Çınar, 'D Köse, ${ }^{2 T}$ Nemut, 'S Altınkaynak. 'Department of Child Health Nursing; ${ }^{2}$ Sakarya University School of Health Sciences, Sakarya, Turkey

Background and Aim Sometimes weaning process may be problem for mothers and their babies. The study was done as descriptive 
in order to define the problems in the process of weaning in breastfed babies.

Methods Sample of the study was consisted with 86 volunteer mothers who registered to 3 different family health center in center of Sakarya province and who have 2 years old children left the breast milk. The data were collected using a questionnaire developed by researchers. The data were analysed using a statistical packet programme.

Results The mean age of the mothers was $29.52 \pm 5.49$. $50.6 \%$ $(n=44)$ of mothers were primary school graduates. $52.9 \% \quad(n=46)$ of families have described to their economic situation as moderate. $47.1 \%(n=41)$ of the mothers $7-12$ months, $27.6 \%$ of $(n=24)$ 0-6 months, $19.7 \%(n=17) 13-24$ months, $5.7 \%$ of $(n=5)$ in 25 months reported weaned the baby. $73.5 \%(n=64)$ of the mothers cut the breastfeeding slowly was determined. Problems experienced by mothers at the beginning of the process of weaning were found as pain in the chest and swelling $(20.7 \% \mathrm{n}=18)$ and maternal stress, anxiety and indecision $(12.6 \% n=11) .39 \%$ of children $(n=34)$ crying, restlessness, irritability and a change in temperament, $12.6 \%(n=11)$ reduction in body weight gain, $8 \%(n=7)$ frequent illness, $2.3 \%(\mathrm{n}=2)$ sleep pattern disorder were reported by their mothers.

Conclusion In the study, various problems occured in children and mothers were found in the process of weaning.

\section{MOTHERS' PERCEIVED FAMILY SUPPORT AND AFFECTING FACTORS IN POSTPARTUM PERIOD}

doi:10.1136/archdischild-2012-302724.1869

N Çınar, D Köse, S Altınkaynak. Department of Child Health Nursing, Sakarya University School of Health Sciences, Sakarya, Turkey

Background and Aim Having a new baby, mothers need the support of relatives due to they often live stress or sometime faced with difficult situations. The study was done as descriptive in order to determine mothers' perceived family support and affecting factors in postpartum period.

Methods Sample of the study was consisted with 140 volunteer mothers in Sakarya. The data were collected using a questionnaire developed by researchers and "Perceived Social Support from Family Scale" (PSS-Fa) developed by Procidana and Hellen (1983) and also validity and reliability made by Eskin (1993).

Results Most of the mothers were determined as $75.7 \%(n=106)$ between the ages of $21-35,87$ and $48.6 \%(n=68)$ primary school graduates. The mean total score of the scale was determined as 14.04 $\pm 4.29(\min =1, \max =20)$. When compared a total score received from the scale with the economic situation of families; Family support were determined as higher $(\mathrm{F}=16.014 \mathrm{p}=0.000)$ in families with moderate and good economic situation compared to the bad economic situation. Between perceived family support and the number of children showed a significant relationship ( $F=3.462$ $\mathrm{p}=0.010$ ). It is determined that when the number of chilren was increased family support was reduced. Relationship between mother's age, employment status and perceived family support were determined as not statistically significant (respectively $\mathrm{F}=.554$ $\mathrm{p}=0.576, \mathrm{t}=0.335 \mathrm{p}=0.738$ ).

Conclusion Mothers in bad economic situation and having more number of children found low perceived family support is remarkable case.

\section{ASSESSING THE INFORMATION AND SUPPORT NEEDS OF PARENTS OF YOUNG CHILDREN IN CANADA}

doi:10.1136/archdischild-2012-302724.1870

${ }^{1} \mathrm{MA}$ Devolin, 'D Phelps, ${ }^{2 \mathrm{~T}}$ Duhaney, ${ }^{3 \mathrm{~K}}$ Benzies, ${ }^{4} \mathrm{C}$ Hildebrandt, ${ }^{4} \mathrm{~S}$ Rikhy, ${ }^{5} \mathrm{~J}$ Churchill,

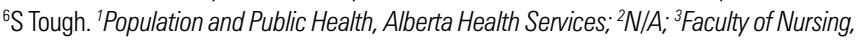

University of Calgary; ${ }^{4}$ Alberta Children's Hospital; ${ }^{5}$ Public Health, Calgary Zone, Alberta Health Services; ${ }^{6}$ Department of Paediatrics, University of Calgary, Calgary, AB, Canada

Aim To determine the parenting information and support needs of parents of young children in an urban center in Canada.

Methods A self-administered survey was mailed to a stratified random sample of 1064 parents of children aged 6 years and under. The survey asked about parents' preferred sources of support, information needs, sources and modes of information delivery and perceived barriers to accessing parenting support services.

Results A $33.7 \%$ response rate was obtained ( $n=359$ surveys). Breastfeeding, car seat safety, caring for a new baby, supporting their child's development and sleep issues were considered 'somewhat' and 'very' important by more than $95.8 \%$ of respondents. Informal sources of support were rated as more important and more valuable than formal supports. The internet, drop-in programs for parents and children, books, organized playgroups, and classes/ information sessions, were identified as the most preferred ways to access parenting information. Parents reported a lack of knowledge and awareness of programs, lack of time, lack of child care, and offered at inconvenient times, as the top barriers to attending parenting services and supports.

Conclusions In general, parents want information on early childhood development and parenting. This assessment contributes to the limited information on the unique needs of parents with children 0-6 years in Canada. The results have important implications for the planning, delivery and dissemination of future parenting education resources, programs and services, namely creating opportunities for social networking and exploring on-line methods for information delivery.

\section{INTERVENTION PROJECT: INTEGRATION OF MATERNITY CARE INTO THE NEONATAL INTENSIVE CARE UNIT, KEEPING MOTHER AND INFANT TOGETHER DIRECTLY AFTER BIRTH}

doi:10.1136/archdischild-2012-302724.1871

L Fredbo-Nielsen. Neonatal Intensive Care Unit, Rigshospitalet, København Ø, Denmark

Background When an infant is born at Rigshospitalet in Denmark, and is transferred to NICU, the bonding between infant and mother is complicated because the mother is transferred to the maternity ward. With the existing knowledge of the infant's congenital competencies to create and preserve relations, the close relation to the mother is necessary for the future development. The competencies includes signals for the infant such as eye contact, crying, sucking on moms breast, smell, rate during communication between mother and infant and smile. A positive and secure bonding predisposes feelings such as basic security, intensity and devotion. Failure and insecure bonding can lead to violent negative feelings. International research shows the benefit of family centered care and skin-to-skin contact for preterm babies and their parents for e.g. temperature, weight gain, sleep, breastfeeding, and bonding.

Aims To facilitate the bonding between the newborn ill infant and the mother.

Methods Transfer of the mother (after normal delivery or 4 hours after planned caesarean) directly to the NICU with her infant.

Two hours training of all 120 neonatal nurses in obstetric nursing. Questionnaire to the mothers.

Results 58 mothers have been transferred directly from the delivery room to NICU. Results from the questionnaire to the mothers will be available on the poster.

Discussion Is it possible for a nurse trained in NICU to take care of the obstetric mother?

Is the environment at NICU acceptable for both mother and infant? 